\title{
Genetic Diversity Study in Sorghum Using Quantitative Morphological Traits
}

\author{
Sweta Sinha*\# and N. Kumaravadivel \\ Dept. of Plant Molecular Biology and Biotechnology, Centre for Plant Molecular Biology, Tamil Nadu Agricultural \\ University, Coimbatore, Tamil Nadu (641 003), India

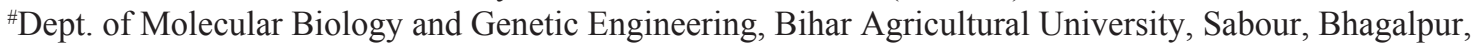 \\ Bihar (813 210), India
}

\section{Article History}

Manuscript No. AR1374

Received in $16^{\text {th }}$ April, 2015

Received in revised form $5^{\text {th }}$ September, 2015

Accepted in final form $5^{\text {th }}$ October, 2015

\section{Correspondence to}

"E-mail: bablysweta@gmail.com

\section{Keywords}

Sorghum, genetic diversity, quantitative trait, cluster, PCA

\begin{abstract}
Assessment of genetic diversity and identification of superior genotypes are important prerequisites for a successful crop improvement program. In the present investigation, 40 sorghum accessions consisting of sweet sorghum, grain sorghum, forage sorghum, mutant lines, maintainer lines and restorer lines, were screened for genetic diversity using quantitative traits. Observations were recorded on 14 quantitative traits, out of which 9 diverse traits contributing to maximum variability were selected for genetic diversity analysis. The principle component analysis revealed that the panicle width, stem girth and leaf breadth, contributed maximum towards divergence. By using hierarchical cluster analysis, the 40 accessions were grouped under 6 clusters. Cluster I contained maximum number of accessions and cluster VI contained the minimum. The maximum inter cluster distance was observed between cluster VI and cluster IV. Cluster III had the highest mean value for hundred seed weight and yield. Hence the accessions falling under these clusters could be used as the parents for hybridization programme in sorghum. Thus, morphological data were able to reveal the existence of a wide genetic diversity among the sorghum accessions used providing scope for further genetic improvement.
\end{abstract}

\section{Introduction}

Sorghum (Sorghum bicolor) is one of the crop species that cansurvive the harsh climatic conditions of the arid environments (Ritter et al., 2007). It is the world's fifth most important cereal, after wheat, rice, maize and barley (Kumar et al., 2011). It is a major food crop in sub-Saharan Africa and South Asia and is the staple food for the most food insecure people in the world (Bibi et al., 2010). Besides being an important food, feed and forage crop, it provides raw material for the production of starch, fiber, dextrose syrup, biofuels, alcohol and other products. Sorghum was domesticated in Africa, from where it was introduced to other regions of the world with diverse agro-climatic conditions. Therefore a wide diversity is found within and among the sorghum cultivars at both phenotypic and genotypic level (Kong et al., 2000). Knowledge of genetic diversity of a crop usually helps the breeder in choosing desirable parents for the breeding program and gene introgression from distantly related germplasm. The more diverse genotypes or accessions can be crossed to produce superior hybrids with resistance to abiotic and biotic stresses. Understanding the wealth of genetic diversity in sorghum will facilitate further improvement of this crop for its genetic architecture (Jayaramachandran et al., 2011).

Genetic diversity in the crop species is the gift of nature and arises due to geographical separation or due to genetic barriers to cross ability. Morphological traits are conventional tools to analyze the genetic diversity. Morphological assay generally require neither sophisticated equipment nor preparatory procedures. They are generally simple and inexpensive to score. These easily observable quantitative morphological traits are useful tool for preliminary evaluation, because they offer a fast and useful approach for assessing the extent of diversity. Until now scientific classification of plant was based on morphological traits (Kumar, 1999). The use of morphological traits is the most common approach utilized to estimate relationships between genotypes. The genetic variability of cultivated species/varieties and their wild relatives together forms a potential and continued source for breeding new and improved crop varieties. Therefore there is a need to evaluate 
the available accessions for genetic diversity. In the present study, an attempt has been made to determine the extent of diversity among 40 sorghum accessions using the quantitative morphological traits.

\section{Materials and Methods}

\subsection{Plant material}

The plant materials consisted of forty accessions of sorghum collected from different parts of Tamilnadu, India. Among these forty accessions, four of accessions were sweet sorghum (SSV84, VMS98001,VMS98002, and VMS98003), seventeen were grain sorghum (APK1, BSR1, Paiyur2, AKS96, AKS109, AKS112,TNS30, TNS342, TNS357, TNS590, K7, K8, K11, $\mathrm{K} 12$, $\mathrm{CO}$ (S) 28, CO20, CO26), two were forage sorghum (CO27 and CO (FS) 29), ten were mutant populations (CO26Tall Plant, CO26-High Yield, CO27-Tall Plant, CO27-High Biomass, CO (S) 28-Bold, CO (S) 28-Tall Plant, CO (S) 28-High Yield, CO (FS) 29-Tall Plant, CO (FS )29-Non Shattering, CO (FS) 29-25 Tiller), three were B-lines (CK60, ICS111, ICS2219) and remaining four accessions were R-lines (IS3541, RS673, RS29, M-35-1). Sinha et al. (2010, 2014) used above accessions of sorghum for association analysis and genetic diversity study using RAPD markers.

\subsection{Methods}

The experiment was conducted at Millet Breeding Station, TNAU, Coimbatore, during Kharif 2005 (Sinha et al., 2010). The accessions were raised in Randomized Block Design (RBD) with two replications. Each accession was raised in a single row of 5 meters length by adopting a spacing of $45 \times 15$ $\mathrm{cm}^{2}$. All the recommended agronomic packages of practices were adopted during the entire crop period. In each replication, five random plants were chosen and the observations were recorded on fourteen traits at the time of maturity except Days to $50 \%$ flowering. Observations consisted of days to $50 \%$ flowering (DFL), days to maturity (DMY), plant height (PHT), panicle length (PNL), panicle width (PWD), leaf length (LFL), leaf breadth (LFW), No. of leaves plant ${ }^{-1}$ (NPL), stem girth (SGT), No. of primary branches panicle ${ }^{-1}$ (NPB), hundred seed weight (HWT), yield plant ${ }^{-1}$ (YLD), panicle weight (PWT) and dry matter production (DMP). The mean values were utilized for statistical analysis to assess the genetic diversity among the accessions.

\subsection{Statistical analysis of quantitative traits}

Prior to analysis the data were standardized to zero mean and unit variance, because various traits were measured on very different scales. The descriptive statistics and correlation coefficients were computed for all the 14 morphological traits using Excel programme.

Factor analysis was performed to know which trait is contributing maximum variability. Principal component analysis of the traits was employed to examine the percentage contribution of each trait to total genetic variation. Agglomerative hierarchical clustering was performed on the Euclidean distance matrix utilizing the Ward's linkage method. These analyses were done using MINITAB software version 1.

\section{Results and Discussion}

The estimation of genetic diversity between different genotypes is the first and foremost process in any crop improvement program for identification of superior genotypes. In the present study, the morphological variation did exist among the 40 sorghum accessions with respect to the 14 traits recorded.

\subsection{Descriptive statistics}

Statistical analysis was carried out with the data on 14 quantitative traits to assess the variability pattern (Table 1). Among all the traits investigated, dry matter production recorded maximum value of mean, standard error, variance, standard deviation, coefficient of variation and range. The descriptive statistics of 14 quantitative indicated the existence of morphological diversity among the sorghum accessions, providing scope for improvement through hybridization and selection.

\begin{tabular}{|c|c|c|c|c|c|c|c|c|c|c|c|c|c|c|}
\hline & DFL & DMY & PHT & PNL & PWD & LFL & LFW & NPL & SGT & NPB & HWT & YLD & PWT & DMP \\
\hline Mean & 66.20 & 104.66 & 182.99 & 24.91 & 7.07 & 62.26 & 6.76 & 8.72 & 4.69 & 47.29 & 2.30 & 35.66 & 47.97 & 450.36 \\
\hline $\begin{array}{l}\text { Standard } \\
\text { Error }\end{array}$ & 0.88 & 0.83 & 7.50 & 1.10 & 0.33 & 1.85 & 0.26 & 0.13 & 0.16 & 1.62 & 0.14 & 1.83 & 2.18 & 27.75 \\
\hline $\begin{array}{l}\text { Standard } \\
\text { Deviation }\end{array}$ & 5.59 & 5.26 & 47.44 & 6.95 & 2.08 & 11.68 & 1.66 & 0.80 & 1.03 & 10.23 & 0.86 & 11.58 & 13.76 & 175.49 \\
\hline $\begin{array}{l}\text { Sample } \\
\text { Variance }\end{array}$ & 31.22 & 27.67 & 2250.37 & 48.27 & 4.32 & 136.50 & 2.77 & 0.65 & 1.06 & 104.57 & 0.74 & 134.14 & 189.31 & 30797.12 \\
\hline Range & 26.00 & 24.00 & 209.60 & 30.90 & 9.95 & 55.05 & 6.55 & 4.05 & 3.80 & 47.50 & 3.45 & 41.50 & 52.00 & 673.50 \\
\hline $\begin{array}{l}\text { Coefficient } \\
\text { of variation }\end{array}$ & 8.44 & 5.03 & 25.92 & 27.89 & 29.43 & 18.77 & 24.62 & 9.22 & 21.96 & 21.62 & 37.37 & 32.47 & 28.68 & 38.97 \\
\hline
\end{tabular}




\subsection{Correlation analysis}

The correlation coefficients of 14 morphological traits were used in characterizing the 40 sorghum accessions. The correlation coefficients of 14 quantitative traits estimated are presented in Table 2 . The high positive and significant correlation value was obtained for panicle weight and hundred seed weight with yield. This was supported by Bakheit, (1989), Senthil and Palanisamy, (1995); Iyanar et al. (2001). The yield was also positively and significantly associated with leaf length, leaf breadth and number of leaves. From these results it is evident that these traits are associated with grain yield and are inter-correlated among them. It indicates that the selection in any one of these yield attributing traits will lead to increase in the other traits, there by finally enhancing the grain yield. Hence, selection for traits like leaf length, leaf breadth, number of leaves plant $^{-1}$, panicle weight and hundred seed weight may also be given importance along with yield.

\subsection{Factor analysis}

Factor analysis was performed in order to reduce a large set of phenotypic traits to a more meaningful smaller set of traits and to know which trait is contributing to maximum variability because genetic improvement depends on the magnitude of genetic variation. Factor analysis provides an exact picture of variability contributed to by each trait. On the basis of factor loadings of the 14 morphological traits that are contributing maximum variability to the first three factors are selected for principal component analysis (Table 3). The first three factors are contributing to $57 \%$ of the total variance observed. The first factor had high contributing factor loadings from stem girth, leaf breadth, leaf length, number of leaves plant ${ }^{-1}$ and number of primary branches panicle ${ }^{-1}$, and contributed to $20.1 \%$ of the total variation. The second factor had high contributing loadings from yield, panicle weight and hundred seed weight and contributed to $19.2 \%$ of the total variation. The third factor had high contributing loadings from panicle length, panicle width, plant height, hundred seed weight and leaf length, and contributed to $17.7 \%$ of total variation. Distribution of biometrical traits in first two factors is shown in loading plot (Figure 1).

\begin{tabular}{lccc}
\hline \multicolumn{4}{l}{ Table 3: Sorted rotated factor loadings of quantitative traits } \\
\hline Variable & Factor 1 & Factor 2 & Factor 3 \\
\hline Stem girth & 0.908 & -0.057 & -0.048 \\
Leaf breadth & 0.858 & -0.371 & 0.089 \\
Leaf length & 0.602 & -0.291 & -0.431 \\
No. of leaves plant ${ }^{-1}$ & 0.565 & -0.384 & 0.005 \\
Yield & 0.217 & -0.955 & -0.019 \\
Panicle weight & 0.202 & -0.939 & 0.038 \\
Hundred seed weight & 0.364 & -0.636 & 0.459 \\
Panicle length & -0.009 & 0.002 & -0.885 \\
Panicle width & 0.253 & 0.058 & -0.796 \\
Plant height & -0.227 & 0.129 & -0.786 \\
Days to maturity & 0.029 & -0.040 & 0.128 \\
Days to 50\% flowering & 0.045 & -0.178 & -0.052 \\
Dry matter production & 0.035 & -0.209 & -0.110 \\
No. of primary branches & 0.476 & -0.122 & 0.071 \\
panicle & & & \\
Variance & & 2.685 & 2.479 \\
\% Variance & 2.810 & 0.192 & 0.177 \\
\hline
\end{tabular}

Table 2: Pearson's correlation coefficients of quantitative traits

\begin{tabular}{|c|c|c|c|c|c|c|c|c|c|c|c|c|c|}
\hline & DFL & DMY & PHT & PNL & PWD & LFL & LFW & NPL & SGT & NPB & HWT & YLD & PWT \\
\hline DMY & $0.752^{* *}$ & & & & & & & & & & & & \\
\hline PHT & -0.011 & -0.241 & & & & & & & & & & & \\
\hline PNL & 0.058 & 0.021 & $0.580^{* *}$ & & & & & & & & & & \\
\hline PWD & -0.054 & -0.186 & $0.564^{* *}$ & $0.596^{* *}$ & & & & & & & & & \\
\hline LFL & 0.069 & -0.184 & 0.159 & 0.253 & $0.386^{*}$ & & & & & & & & \\
\hline LFW & 0.126 & 0.035 & -0.265 & -0.076 & 0.137 & $0.578^{* *}$ & & & & & & & \\
\hline NPL & 0.278 & 0.263 & -0.072 & 0.008 & 0.052 & 0.252 & $0.564^{* *}$ & & & & & & \\
\hline SGT & 0.060 & 0.104 & -0.180 & 0.051 & 0.264 & $0.477^{* *}$ & $0.741^{* *}$ & $0.576^{* *}$ & & & & & \\
\hline NPB & -0.048 & -0.299 & 0.156 & -0.171 & 0.120 & 0.282 & $0.525^{* *}$ & 0.309 & $0.319^{*}$ & & & & \\
\hline HWT & 0.221 & 0.227 & $-0.440^{* *}$ & $-0.408^{* *}$ & -0.189 & 0.121 & $0.649^{* *}$ & $0.455^{* *}$ & $0.352^{*}$ & $0.343^{*}$ & & & \\
\hline YLD & 0.230 & 0.121 & -0.147 & 0.013 & 0.021 & $0.361^{*}$ & $0.525^{* *}$ & $0.547^{* *}$ & 0.292 & 0.235 & $0.668^{* *}$ & & \\
\hline PWT & 0.305 & 0.138 & -0.131 & -0.070 & -0.018 & $0.320^{*}$ & $0.521^{* *}$ & $0.537^{* *}$ & 0.286 & 0.286 & $0.707^{* *}$ & $0.961^{* *}$ & \\
\hline DMP & 0.153 & 0.002 & $0.327^{*}$ & -0.064 & 0.212 & 0.078 & 0.187 & 0.254 & 0.176 & 0.271 & $0.320^{*}$ & 0.264 & $0.325^{*}$ \\
\hline
\end{tabular}




\subsection{Principal component analysis}

A set of 9 diverse quantitative traits selected from the 14 traits namely, stem girth, leaf breadth, leaf length, number of leaves plant ${ }^{-1}$, number of primary branches panicle ${ }^{-1}$, yield, hundred seed weight, panicle width and plant height and were used to group the accessions based on principal component. The first three principal components accounted for $73.2 \%$ of the total variance (Table 4). The first principal component (PC1) accounted for $41.7 \%$ of total variance, and had high contributing factor loadings from leaf breadth, stem girth, number of leaves plant ${ }^{-1}$, hundred seed weight and yield. The second principal component (PC2) had high contributing factor loadings from panicle width, plant height, leaf length and hundred seed weight and contributed to $21.8 \%$ of the total variation. The third principal component (PC3) accounted to

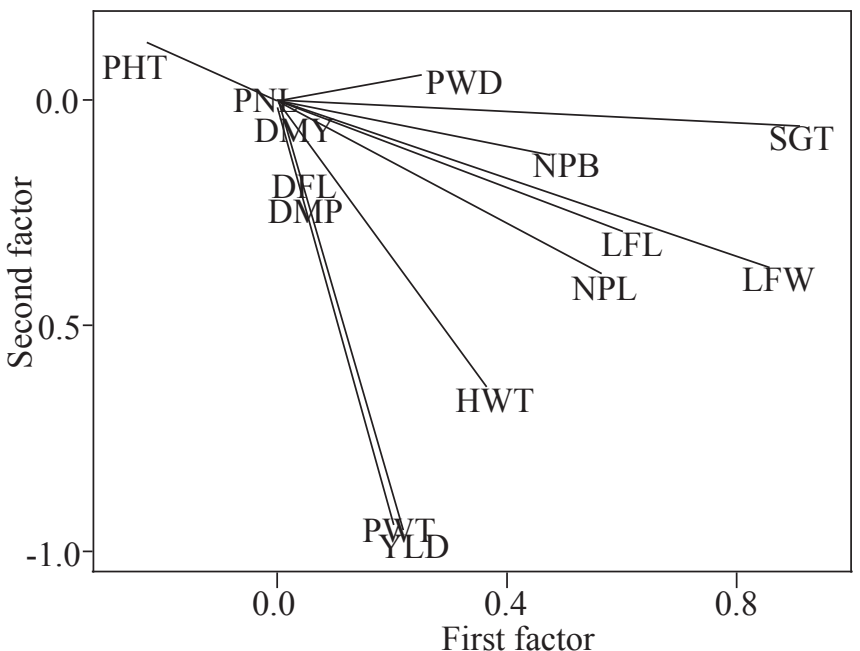

Figure 1: Loading plot of quantitative traits based on factor analysis

Table 4: Principal components analysis showing the contribution of 9 characters among the sorghum accessions

\begin{tabular}{|c|c|c|c|}
\hline Traits & $\mathrm{PC} 1$ & $\mathrm{PC} 2$ & $\mathrm{PC} 3$ \\
\hline Stem Girth & 0.396 & -0.113 & 0.486 \\
\hline Leaf breadth & 0.477 & -0.004 & 0.146 \\
\hline Leaf length & 0.302 & -0.353 & 0.281 \\
\hline No. of leaves plant ${ }^{-1}$ & 0.381 & 0.024 & -0.083 \\
\hline No. of primary branches panicle ${ }^{-1}$ & 0.286 & -0.158 & -.0547 \\
\hline Yield plant ${ }^{-1}$ & 0.371 & 0.117 & -0.317 \\
\hline Hundred seed weight & 0.377 & 0.336 & -0.256 \\
\hline Panicle width & 0.078 & -0.602 & 0.097 \\
\hline Plant height & -0.112 & -0.590 & -0.426 \\
\hline Eigen Value & 3.753 & 1.960 & 0.876 \\
\hline$\%$ Variance & 41.70 & 21.80 & 9.70 \\
\hline Cumulative $\%$ variance & 41.70 & 63.50 & 73.20 \\
\hline
\end{tabular}

$9.7 \%$ of the total variation, with high factor loadings for number of primary branches panicle ${ }^{-1}$, stem girth, plant height, yield and leaf length. The score plot of 40 accessions based on the first two principal components is presented in Figure 2. The PCA analysis revealed that the panicle width, stem girth and leaf breadth, contributed maximum towards divergence.

\subsection{Cluster analysis}

Agglomerative hierarchical clustering performed on the Euclidean distance matrix utilizing the Ward's linkage method and resulting dendrogram is presented in Figure 3. The 40 sorghum accessions formed 6 clusters at $25.04 \%$ similarity level. Among the different clusters, the cluster size varied from 3 to 12 . The maximum number of accessions was included in cluster I having 12 accessions and the minimum number in cluster VI having 3 accessions. The cluster I consisted of sweet sorghum, grain sorghum and restorer lines. The cluster II consisted of sweet sorghum, grain sorghum and $\mathrm{CO}$ (S) 28 mutants. The cluster III consisted of grain sorghum, restorer lines and CO26 mutant and CO (S) 28 mutant. The cluster IV consisted of grain sorghum and maintainer lines. The cluster V and cluster VI consisted of forage sorghum and its mutant. The clustering pattern indicated the existence of significant amount of variability among the grain sorghum.

The highest inter cluster distance was observed between cluster IV and VI (5.148), the accessions from those clusters if chosen for hybridization program, may give broad spectrum of variability in segregating generation (Table 5). The lowest inter-cluster distance was observed between II and III (2.133). The clusters contributing maximum to the divergence were given greater emphasis for deciding the type of cluster for the purpose of further selection and the choice of the parents of

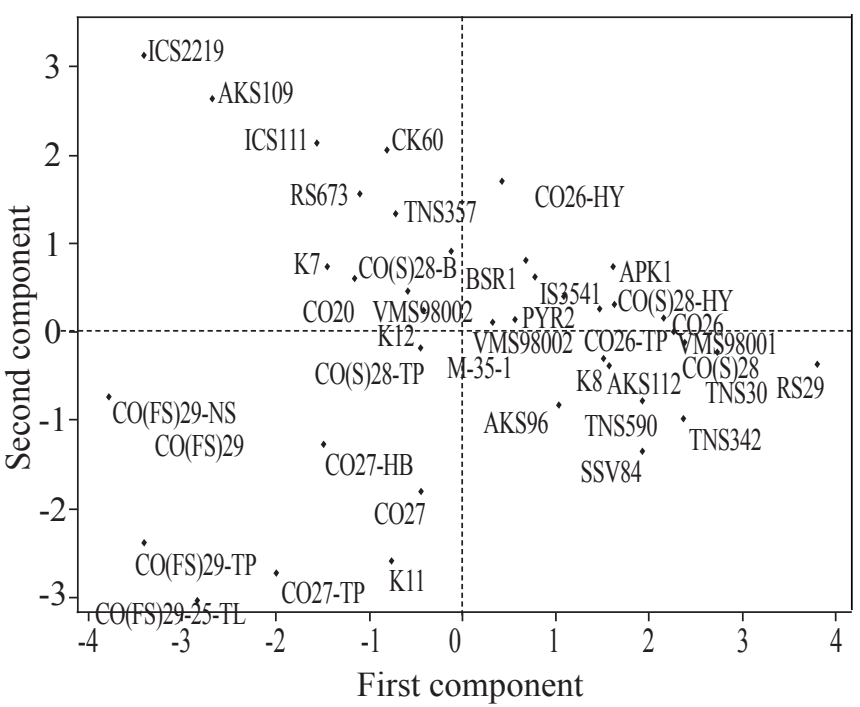

Figure 2: Distribution of sorghum accessions for first two principal components based on nine quantitative traits 


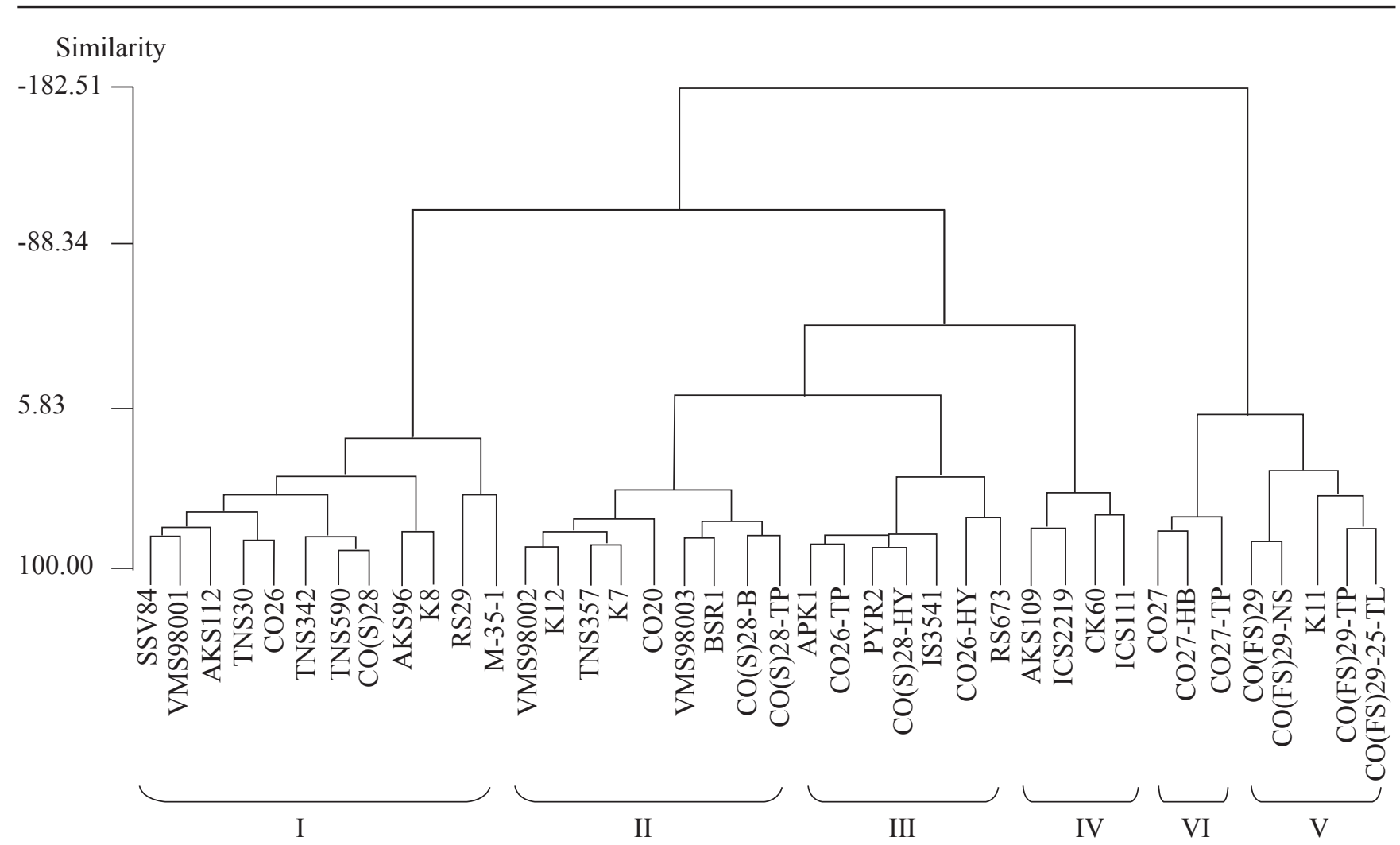

Figure 3: Dendrogramof sorghum accessions based on nine quantitative traits

hybridization (Rohman et al., 2004).

The cluster mean of the six similarity cluster groups in the 40 sorghum accessions are presented in Table 6. Cluster I had the highest mean values for leaf length (71.17), leaf breadth (8.41), number of leaves plant ${ }^{-1}$ (9.42) and stem girth (5.84). Cluster II showed moderate mean values for leaf length, leaf width, stem girth and hundred seed weight. Cluster III had the highest mean values for hundred seed weight (2.99) and yield (50.00). Cluster IV had the lowest mean values for plant height (97.03) and panicle width (4.00). Cluster V had the highest mean values for panicle width (9.26). Cluster VI had the highest mean values for plant height (255.92) and number of primary branches panicle ${ }^{-1}$ (59.83). Based on the cluster means, the important cluster is cluster III which had the highest mean values for hundred seed weight and yield. Hence the

\begin{tabular}{lcccccc}
\hline \multicolumn{7}{c}{ Table 5: Inter cluster distances among sorghum accessions } \\
\hline \multicolumn{1}{c}{$\begin{array}{c}\text { Clus- } \\
\text { ter I }\end{array}$} & $\begin{array}{c}\text { Clus- } \\
\text { ter II }\end{array}$ & $\begin{array}{c}\text { Clus- } \\
\text { ter III }\end{array}$ & $\begin{array}{c}\text { Clus- } \\
\text { ter IV }\end{array}$ & $\begin{array}{c}\text { Clus- } \\
\text { ter V }\end{array}$ & $\begin{array}{c}\text { Clus- } \\
\text { ter VI }\end{array}$ \\
\hline Cluster I & 0.000 & & & & & \\
Cluster II & 2.813 & 0.000 & & & & \\
Cluster III & 2.343 & 2.133 & 0.000 & & & \\
Cluster IV & 5.088 & 2.955 & 4.168 & 0.000 & & \\
Cluster V & 5.125 & 3.823 & 4.827 & 4.705 & 0.000 & \\
Cluster VI & 4.260 & 3.105 & 4.150 & 5.148 & 3.188 & 0.000 \\
\hline
\end{tabular}

Table 6: Characteristic means of six similarity cluster groups of sorghum accessions

\begin{tabular}{lcccccc}
\hline Traits & I & II & III & IV & V & VI \\
\hline $\begin{array}{l}\text { Plant } \\
\text { height } \\
\text { Panicle } \\
\text { width }\end{array}$ & 178.40 & 164.68 & 181.16 & 97.03 & 254.45 & 255.92 \\
$\begin{array}{l}\text { Leaf } \\
\text { length }\end{array}$ & 71.17 & 57.54 & 62.76 & 46.13 & 56.74 & 69.40 \\
$\begin{array}{l}\text { Leaf } \\
\text { breadth }\end{array}$ & 8.41 & 6.76 & 6.74 & 5.36 & 3.54 & 6.50 \\
$\begin{array}{l}\text { No. of } \\
\text { leaves } \\
\text { plant }{ }^{-1}\end{array}$ & 9.42 & 8.28 & 9.14 & 8.13 & 8.15 & 7.82 \\
$\begin{array}{l}\text { Stem } \\
\text { girth }\end{array}$ & 5.84 & 4.37 & 4.31 & 4.14 & 3.36 & 4.05 \\
$\begin{array}{l}\text { No. of } \\
\text { primary } \\
\text { branches } \\
\text { panicle }\end{array}$ & 50.50 & 49.00 & 50.79 & 32.00 & 34.81 & 59.83 \\
$\begin{array}{l}\text { Hundred } \\
\text { seed } \\
\text { weight }\end{array}$ & 2.68 & 2.59 & 2.99 & 1.94 & 0.60 & 1.17 \\
$\begin{array}{l}\text { Yield } \\
\text { plant }\end{array}$ & 42.39 & 30.63 & 50.00 & 25.79 & 26.13 & 21.67 \\
\hline
\end{tabular}


accessions falling under these clusters could be used as the parents for hybridization programme.

\section{Conclusion}

This study provides wide range and the variance of 14 quantitative traits indicated the existence of morphological diversity. Correlation studies clearly showed that the traits namely, leaf length, leaf breadth, number of leaves plant ${ }^{-1}$ panicle weight and hundred seed weight had significant and positive association with yield. By using principle component analysis and hierarchical cluster analysis, the 40 accessions were grouped under 6 clusters. The selection of parents must be based on the wider inter cluster distance and superior mean performance for yield and yield components.

\section{Further Research}

Genetic diversity analysis with proper phenotyping in multiple locations will help the breeders to mine for trait-specific alleles and facilitate an effective method of identifying the gene/QTL for different quantitative traits through association mapping.

\section{References}

Bakheit, B.R., 1989. Variability and correlations in grain sorghum genotypes under drought conditions at different stages of growth. Asian Journal of Agricultural Sciences 20(4), 227-252.

Bibi, A., Sadaqat, H.A., Akram, H.M., Mohammed, M.I., 2010. Physiological markers for screening sorghum (Sorghum bicolor) germplasm under stress condition. International Journal of Agriculture and Biology 12, 451-455.

Iyanar, K., Gopalan, A., Ramasamy, P., 2001. Correlation and path analysis in sorghum. Annals of Agricultural Research New Series 22(4), 495-497.
Jayaramachandran, M., Kumaravadivel, N., Kandasamy, G., Eapen, Susan., 2011. Comparison of Genetic Variability Induced by $\gamma$ Radiation and Tissue Culture in Sorghum. International Journal of Bio-resource and Stress Management 2(3), 329-333.

Kong, L., Dong, J., Har, G.E., 2000. Characteristics, linkagemap positions, and allelic differentiation of Sorghum bicolor (L.) Moench. DNA simple-sequence repeats (SSRs). Theoretical and Applied Genetics 101, 438-448.

Kumar, L.S., 1999. DNA markers in plant improvement: An overview. Biotechnology Advances 17(2-3), 143-182.

Kumar, A.A., Reddy, B.V.S., Sharma, H.C., Hash, C.T., Rao, P.S., Ramaia, B., Reddy, P.S., 2011. Recent advances in sorghum genetic enhancement research at ICRISAT. American Journal of Plant Science 2, 589-600.

Ritter, K.B., McIntyre, C.L., Godwin, I.D., Jordan, D.R., Chapman, S.C., 2007. An assessment of the genetic relationship between sweet and grain sorghums, within Sorghum bicolor ssp. bicolor (L.) Moench, using AFLP markers. Euphytica 157, 161-176.

Rohman, M.M., Hakim, M.A., Sultana, N.A., Kabir, M.E., Hasanuzzan, M., Ali, M., 2004. Genetic divergence analysis in sorghum (Sorghum bicolor L.). Asian Journal of Plant Sciences 3(2), 211-214.

Senthil, N., Palanisamy, S., 1995. Character association and path analysis in sorghum. Madras Agriculture Journal 82, 169-170.

Sinha, S., Kumaravadivel, N., 2010. Association analysis of agronomically important traits using RAPD markers in sorghum accessions. International Journal of Agriculture, Environment and Biotechnology 3(2), 241-245.

Sinha, S., Kumaravadivel, N., Eapen, Susan., 2014. RAPD Analysis in Sorghum [Sorghum bicolor (L.) Moench] Accessions. International Journal of Bio-resource and Stress Management 5(3), 381-385. 